\title{
The Bragg Reflector Layer of Low Surface Roughness Based on Solidly Mounted Resonators
}

\author{
Wei-Che Shih ${ }^{\mathrm{a}}$, Ying-Chung Chen ${ }^{\mathrm{a}}$, Wei-Tsai Chang ${ }^{\mathrm{a}}$, Chien-Chuan Cheng ${ }^{\mathrm{b}}{ }^{*}, \mathrm{~K}^{*}$ Kuo-Sheng Kao ${ }^{\mathrm{c}}$, Kuo-Hua Cheng ${ }^{\mathrm{c}}$, \\ Chih-Ming Wang ${ }^{d}$, Chih-Yu Wen ${ }^{a}$, Jui-Yang Chang ${ }^{a}$ and Po-Wei Ting ${ }^{a}$ \\ ${ }^{\mathrm{a}}$ Department of Electrical Engineering, National Sun Yat-Sen University, Kaohsiung, Taiwan \\ ${ }^{\mathrm{b}}$ Department of Electronic Engineering, De Lin Institute of Technology, Taipei, Taiwan \\ ${ }^{\mathrm{c}}$ Department of Computer and Communication, Shu-Te University, Kaohsiung, Taiwan \\ ${ }^{\mathrm{d}}$ Department of Electrical Engineering, Cheng-Shiu University, Kaohsiung, Taiwan
}

*Corresponding Author: chengccc@dlit.edu.tw

\begin{abstract}
In this study, the solidly mounted resonator (SMR) device is composed of a piezoelectric layer sandwiched between two electrodes on a Bragg reflector attached to a silicon substrate. To obtain appropriate SMR characteristics for the new-generation communication applications, the surface roughness of Bragg reflector has been investigated thoroughly.

Manufacture parameters are adjusted in accordance with the results of atomic force microscopy (AFM) and scanning electron microscopy (SEM). The frequency response is measured using an HP8720 network analyzer and a CASCADE probe station.

Afterwards, a $1 / 4 \lambda$ mode SMR is experimentally realized. The surface roughness of $6.442 \mathrm{~nm}$ and well return loss can be achieved for four-pair $\mathrm{SiO}_{2} / \mathrm{Mo} \mathrm{Bragg}$ reflector.
\end{abstract}

Keywords: SMR, Bragg reflector layer, $\mathrm{SiO}_{2}, \mathrm{Mo}$, AlN

\section{Introduction}

In recent year, the issue of the frequency bandwidth of wireless communication systems is being of great interest and attention. The global systems for mobile communication could be classified into four types of systems, GSM850/GSM900 band, DCS (GSM1800), WCDMA, and LTE. Thence, several acoustic devices were investigated for high frequency band such as nano-scaled surface acoustic wave (SAW) resonator ${ }^{(1)}$, thin-film bulk acoustic resonator (TFBAR) ${ }^{(2,3)}$ and SMR.
The high frequency SAW devices have some advantages, such as small size, simple structure and good reproducibility. However, it is difficult to manufacture nano-scale interdigital transducer electrodes (IDTs) through conventional methods. Nowadays, the nano-scale IDTs can be obtained using E-beam direct write lithography method, but its cost is expensive.

TFBAR and SMR devices have been widely investigated because they have many advantages such as low insertion loss, low cost, high power handling capability, and small size. There are two kinds of TFBAR structure to avoided acoustic energy dissipation in substrate, including air gap isolated resonator and via isolated resonator ${ }^{(4-10)}$, as shown in Fig. 1(a) and (b). The air gap isolated resonator and via isolated resonator were formed using etching process to obtain a cavity, but the cavity-based structure is easily destroyed in etching processes. On the other hand, the SMR structure is fabricated using planar processes. This better mechanical structure makes it easy to package and integrate with an $\mathrm{IC}^{(11-13)}$, as shown in Fig. 1(c).

Despite the use of various piezoelectric films in transducer devices, including lead zirconate titanate (PZT), zinc oxide $(\mathrm{ZnO})$, and aluminum nitride (AIN) thin films, most of the many studies of piezoelectric thin films have focused on $\mathrm{ZnO}$ and AlN thin films. This study concerns piezoelectric thin films of AlN, whose high quality factor make them suitable for using in the new-generation communication system. 


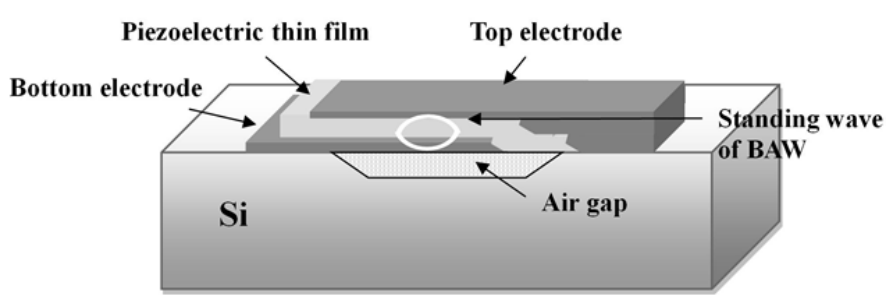

(a)

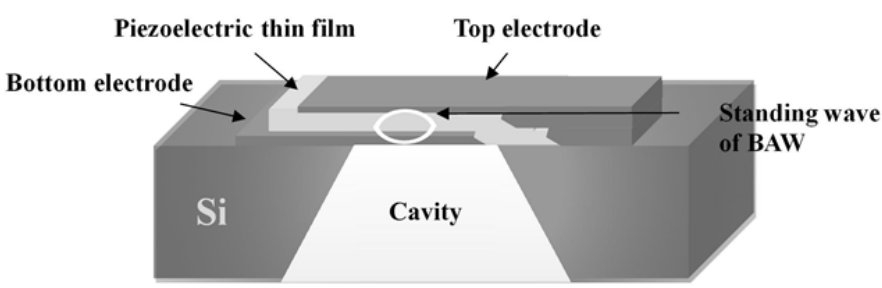

(b)

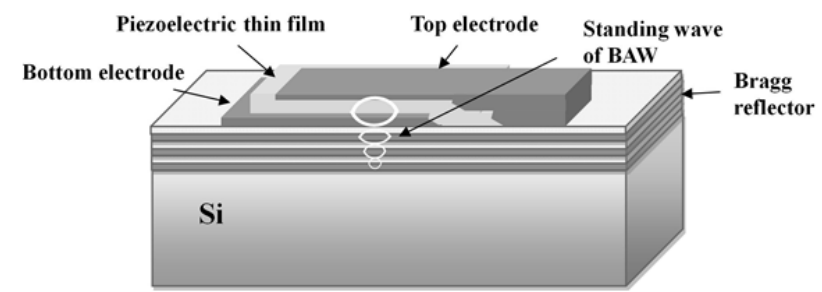

(c)

Fig. 1. The three kinds of TFBAR structure, (a) air gap isolated resonator, (b) via isolated resonator and (c) SMR.

The SMR device is composed of a piezoelectric layer sandwiched between two electrodes on a Bragg reflector attached to a silicon substrate. In the Bragg reflector, high/low acoustic impedance materials in one quarter acoustic wavelength thin films are successively stacked onto the substrate to maintain the required resonant boundary conditions to avoid wave energy dissipation into the substrate. Hence, the surface roughness of the Bragg reflector layer is the key factor to avoid acoustic-energy scattering. It is believed that increasing the numbers of paired Bragg reflector layers will increase the reflection coefficient and yield better resonance property. Moreover, the surface roughness is varied with the numbers of paired Bragg reflector layers ${ }^{(14)}$. Therefore, the effect of $\mathrm{SiO}_{2} / \mathrm{Mo}$ numbers on the frequency response will be discussed.

\section{Experimental}

Above all, the silicon wafers were cleaned using a normal process, as shown in Fig. 2. The $\mathrm{SiO}_{2} / \mathrm{Mo}$ layer was deposited by DC and RF sputtering system to form a Bragg reflector layer. Sputtering pressure and sputtering power were modulated to obtain smooth surface structure. The deposition parameters of Bragg reflector layer were described in Table I.

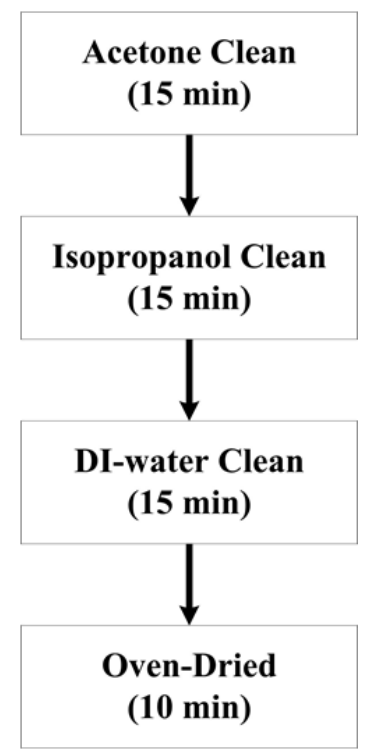

Fig. 2. The silicon wafers were cleaned using a normal process

Table I. The sputtering parameters of $\mathrm{SiO}_{2} /$ Mo layer

\begin{tabular}{|c|c|c|}
\hline & $\mathrm{Mo}$ & $\mathrm{SiO}_{2}$ \\
\hline Base pressure (mTorr) & $3 \times 10^{-3}$ & $3 \times 10^{-3}$ \\
\hline Sputtering pressure (mTorr) & $1 \sim 9$ & $10 \sim 20$ \\
\hline Sputtering power $(\mathrm{W})$ & $1 \sim 9$ & $100 \sim 150$ \\
\hline Substrate temperature $\left({ }^{\circ} \mathrm{C}\right)$ & R. T. & 350 \\
\hline Ar flow $(\mathrm{sccm})$ & 10 & 10 \\
\hline
\end{tabular}

The Ti and Pt thin films were adopted as bottom and top electrodes for SMR devices because of its high electrical conductivity and chemical stable. The Pt/Ti thin films were deposited using DC sputtering system and the AlN piezoelectric thin films were deposited using reactive radio-frequency (RF) magnetron sputtering system. Next, the Ti and Pt thin films were deposited on AlN thin films as top electrodes. The sputtering parameters of $\mathrm{Ti}, \mathrm{Pt}$, and $\mathrm{AlN}$ thin films were presented in Table II and III, respectively.

Table II. The sputtering parameters of Pt/Ti layer

\begin{tabular}{|c|c|c|}
\hline & $\mathrm{Ti}$ & $\mathrm{Pt}$ \\
\hline Base pressure (mTorr) & \multicolumn{3}{|c|}{$3 \times 10^{-3}$} \\
\hline Sputtering pressure (mTorr) & 3 & 1 \\
\hline Sputtering power $(\mathrm{W})$ & 75 & 175 \\
\hline Substrate temperature $\left({ }^{\circ} \mathrm{C}\right)$ & \multicolumn{3}{|c|}{ R.T. } \\
\hline Ar flow $(\mathrm{sccm})$ & \multicolumn{2}{|c|}{10} \\
\hline
\end{tabular}


Table III. The sputtering parameters of AlN thin films

\begin{tabular}{|c|c|}
\hline & $\mathrm{Al}(99.9995 \%)$ \\
\hline Base pressure (mTorr) & $5 \times 10^{-4}$ \\
\hline Sputtering pressure (mTorr) & 5 \\
\hline Sputtering power $(\mathrm{W})$ & 230 \\
\hline Substrate temperature $\left({ }^{\circ} \mathrm{C}\right)$ & 300 \\
\hline $\mathrm{N}_{2} / \mathrm{N}_{2}+$ Ar flow $(\%)$ & 60 \\
\hline
\end{tabular}

\section{Results and Discussion}

\subsection{Structural and morphological properties of Bragg reflector layer}

\subsubsection{Analysis of Mo thin films}

The deposition parameters were modulated to obtain smooth surface structure of $\mathrm{SiO}_{2} / \mathrm{Mo}$ thin films. Firstly, five sputtering pressures with RF power of $100 \mathrm{~W}$ were used to study the phenomenon of Mo thin films. As shown in Fig. 3, a sputtering pressure of $7 \mathrm{mTorr}$ resulted in the low surface roughness. Therefore, the sputtering pressure was fixed at 7 mTorr to produce a smooth surface structure of Mo thin films.

Then, the sputtering power was controlled to investigate the influence of surface roughness. Figure 4 presents the surface roughness of the Mo thin film deposited on the $\mathrm{Si}$ substrates with various sputtering powers. The optimize low surface roughness of Mo thin films can be obtained through sputtering pressure of 7 mTorr and the sputtering power of $100 \mathrm{~W}$.

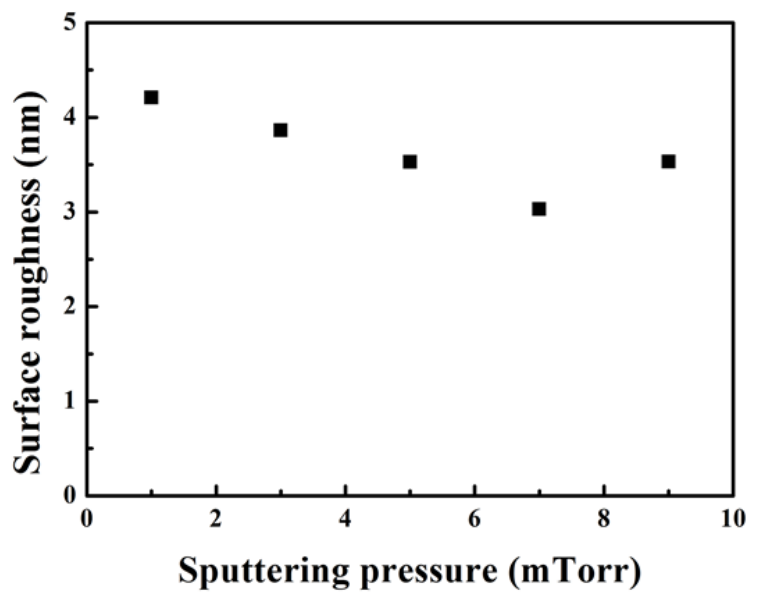

Fig. 3. The surface roughness of Mo thin films with various sputtering pressure.

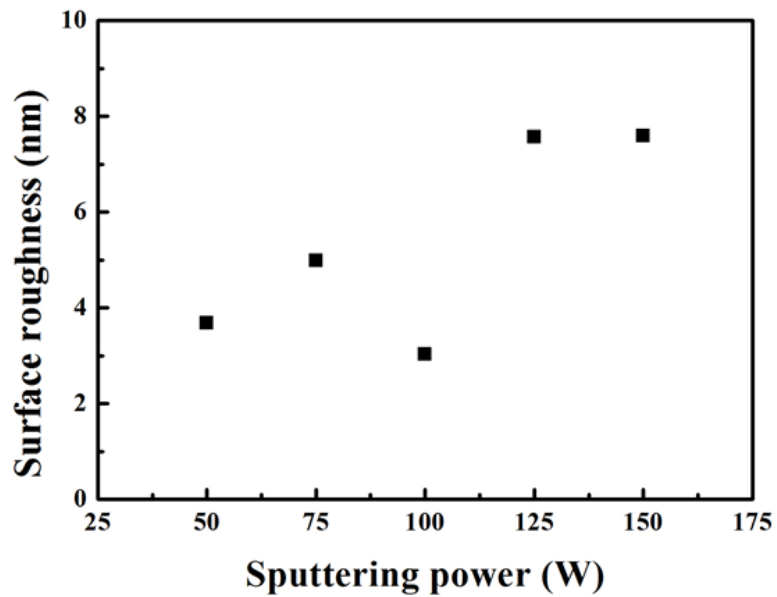

Fig. 4. The surface roughness of Mo thin films with various sputtering power.

\subsubsection{Analysis of $\mathrm{SiO}_{2}$ thin films}

Secondly, the $\mathrm{SiO}_{2}$ thin films were deposited on the Mo thin films using RF sputtering systems. The sputtering pressure and sputtering power were controlled to improve the surface roughness of $\mathrm{SiO}_{2}$ thin films. The sputtering pressure was controlled from $10 \mathrm{~m}$ Torr to $30 \mathrm{mTorr}$ and the sputtering power was set at $150 \mathrm{~W}$ to investigate the effect of the sputtering pressure on $\mathrm{SiO}_{2}$ thin films. Fig. 5 shows the lower surface roughness can be obtained using sputtering pressure of 20 mTorr. Next, the sputtering pressure was set at 20 mTorr and sputtering power was controlled from $100 \mathrm{~W}$ to $150 \mathrm{~W}$ to investigate the influence of sputtering power on $\mathrm{SiO}_{2}$ thin films. From the Fig. 6, the sputtering power of $150 \mathrm{~W}$ exhibited the lower surface roughness than other sputtering power. Therefore, the optimize low surface roughness of $\mathrm{SiO}_{2}$ thin films can be obtained through sputtering pressure of $20 \mathrm{mTorr}$ and the sputtering power of $150 \mathrm{~W}$.

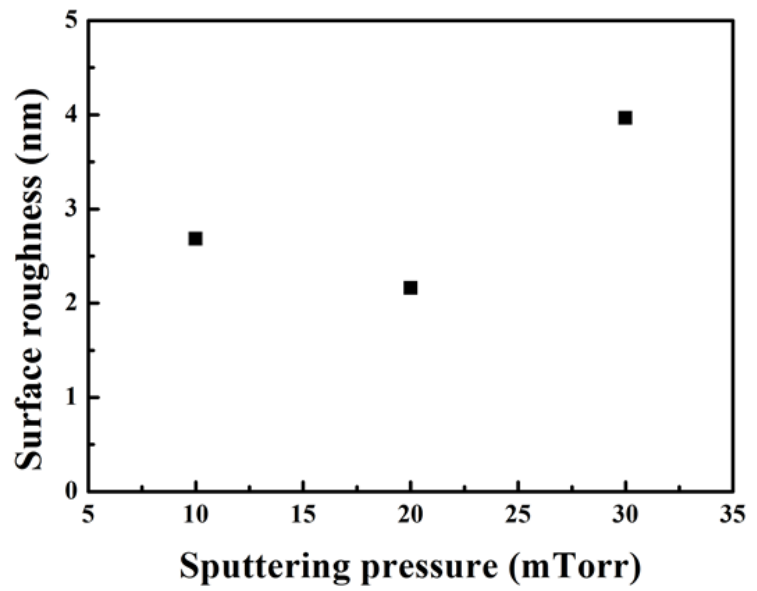

Fig. 5. The surface roughness of $\mathrm{SiO}_{2}$ thin films with various sputtering pressure. 


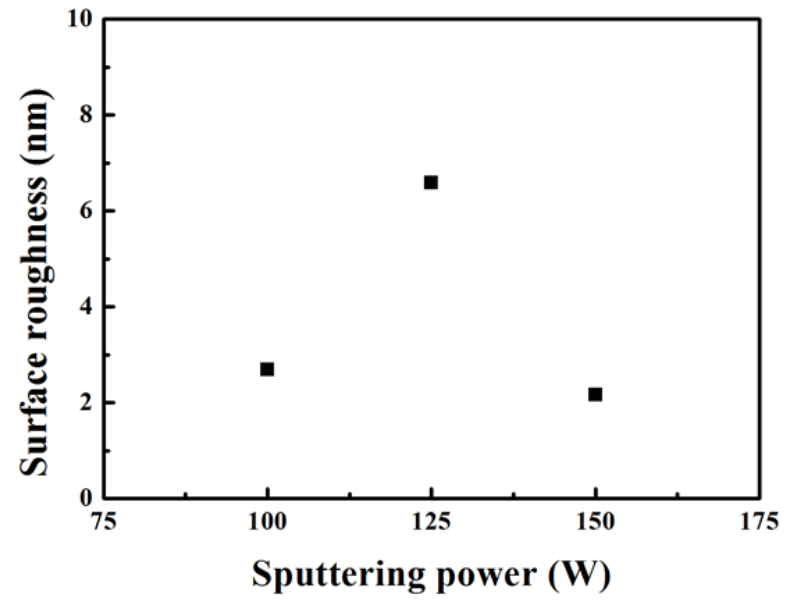

Fig. 6. The surface roughness of $\mathrm{SiO}_{2}$ thin films with various sputtering power.

\subsection{Frequency response of SMR with 3 and 4 pairs $\mathrm{SiO}_{2} / \mathrm{Mo}$}

As shown in Fig. 7 and Fig. 8, the 3-pair and 4-pair of $\mathrm{SiO}_{2} / \mathrm{Mo}$ layer exhibit smooth and clear interfaces morphology.

Figure. 9 shows the frequency responses of SMR device with 3-pair and 4-pair $\mathrm{SiO}_{2} / \mathrm{Mo}$. The smooth and low surface roughness can be obtained by $\mathrm{SiO}_{2} / \mathrm{Mo}$ consisting Bragg reflector layer, and the 4-pair of $\mathrm{SiO}_{2} / \mathrm{Mo}$ layer of root mean square $\left(R_{m s}\right)$ was $6.442 \mathrm{~nm}$, as shown in Fig. 9 (a). The well return loss can be obtained $-21.5 \mathrm{~dB}$ through $\mathrm{SiO}_{2} / \mathrm{Mo}$ constructed Bragg reflector layer.

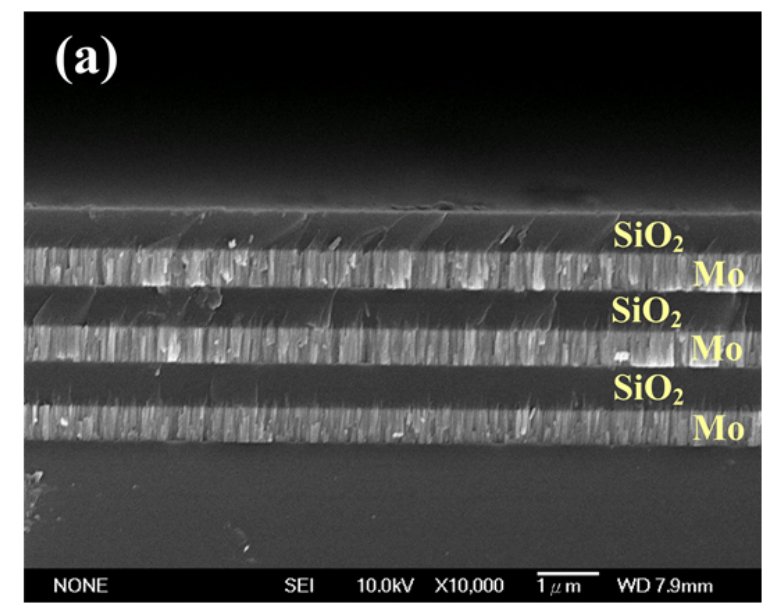

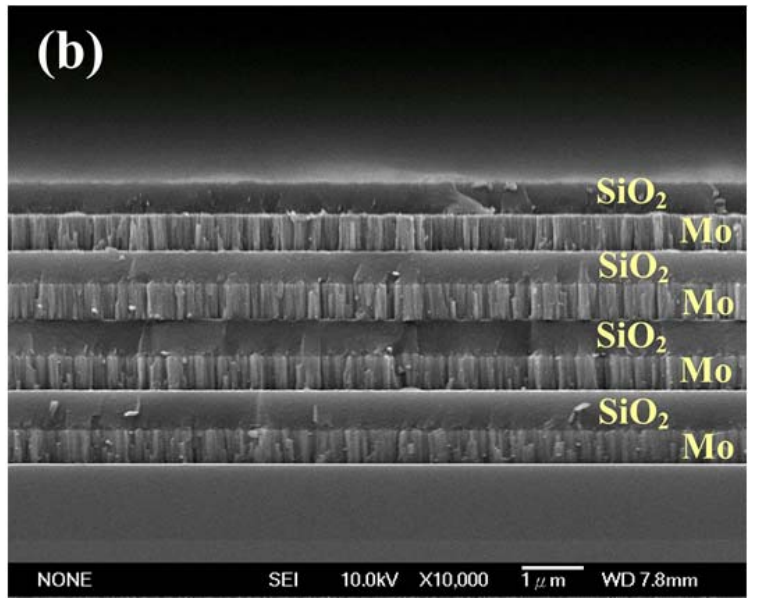

Fig. 7. The cross-sectional SEM image of Bragg reflector layer with (a) 3-pair and (b) 4-pair $\mathrm{SiO}_{2} / \mathrm{Mo}$

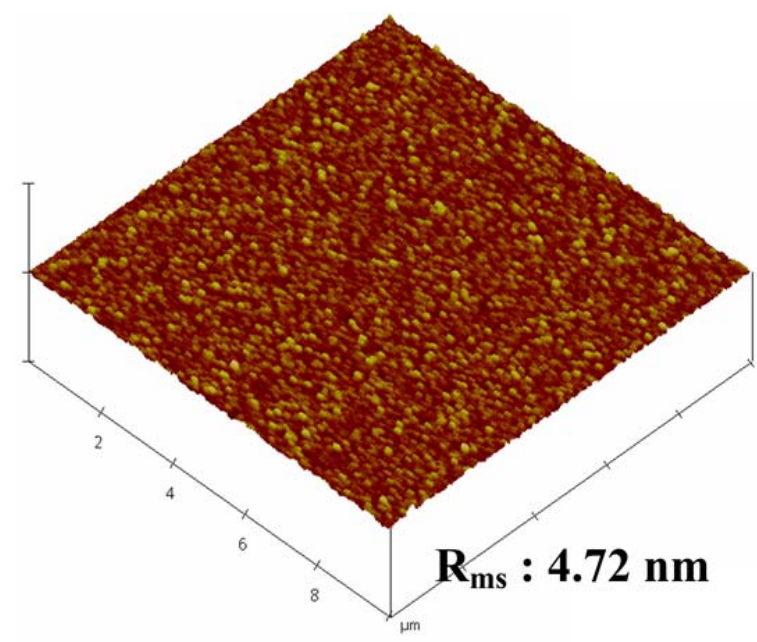

(a)

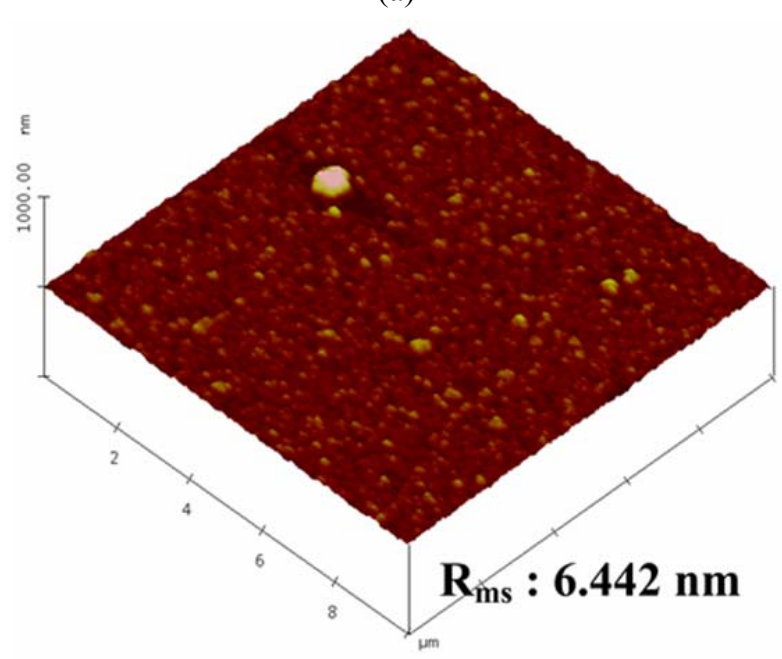

(b)

Fig. 8. The AFM image of Bragg reflector layer with (a) 3-pair and (b) 4-pair $\mathrm{SiO}_{2} / \mathrm{Mo}$ 


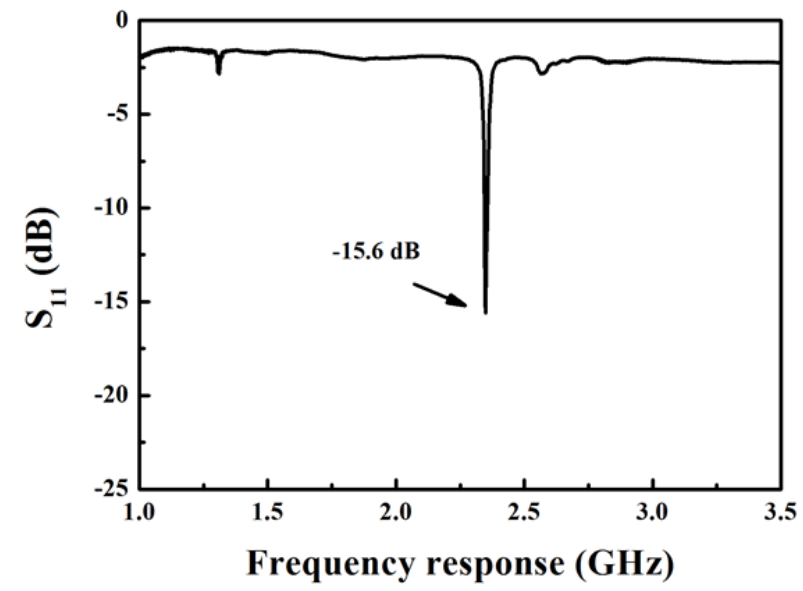

(a)

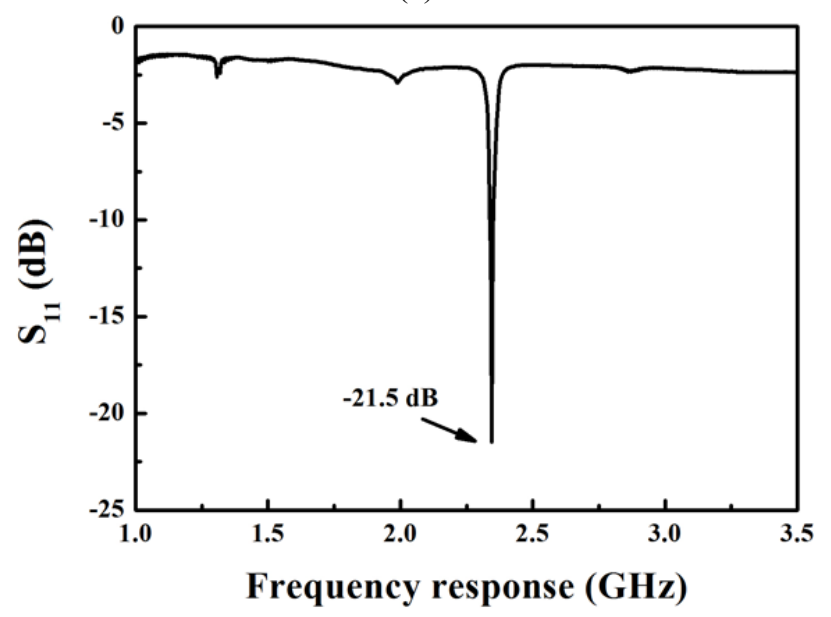

(b)

Fig. 9. The frequency response with (a) 3-pair and (b) 4-pair $\mathrm{SiO}_{2} / \mathrm{Mo}$

\section{Conclusions}

In this study, the SMR devices were composed of $\mathrm{Pt} / \mathrm{Ti} / \mathrm{AlN} / \mathrm{Pt} / \mathrm{Ti}$ and combined with Bragg reflector layer. The low surface roughness of Bragg reflector layer was consisted using 3-pair and 4-pair $\mathrm{SiO}_{2} / \mathrm{Mo}$ and the AFM image presents surface roughness of $4.72 \mathrm{~nm}$ and $6.442 \mathrm{~nm}$, respectively. The SMR devices of surface roughness and well return loss can be obtain $6.442 \mathrm{~nm}$ and $-21.5 \mathrm{~dB}$ through 4-pair Bragg reflector layer.

\section{Acknowledgment}

The authors gratefully acknowledge financial support from the National Science Council, the Republic of China (NSC Grant Numbers: No. NSC 102-2221-E-366-002, and NSC 102-2221-E-110-029) and from the National Sun Yat-sen University (The Aim for the Top University Project, NSYSU).

\section{References}

(1) W. C. Shih, Y. C. Chen, W. T. Chang, C. C. Cheng, P. C. Liao, and K. S. Kao : "Design and Fabrication of Nanoscale IDTs Using Electron Beam Technology for High-Frequency SAW Devices", Journal of Nanomaterials, 2014, Article ID 643672, 2014.

(2) C. J. Chung, Y. C. Chen, C. C. Cheng, C. L. Wei, and K. S. Kao : "Influence of surface roughness of Bragg reflectors on resonance characteristics of solidly-mounted resonators", IEEE transactions on ultrasonics ferroelectrics and frequency control, 54, 802-808, 2007.

(3) C. J. Chung, Y. C. Chen, C. C. Cheng, and K. S. Kao : "Synthesis and bulk acoustic wave properties in the dual mode frequency shift of solidly mounted resonators", IEEE transactions on ultrasonics ferroelectrics and frequency control, 55, 857-864, 2008.

(4) R. C. Ruby, P. Bradley, Y. Oshmyansky, and A. Chien : "Thin film bulk wave acoustic resonators (FBAR) for wireless applications", IEEE Ultrasonics Symposium, 1, 813-821, (2001).

(5) J. D. Larson, R. C. Ruby, P. D. Bradley, J. Wen, S.L. Kok, and A. Chien : "Power handling and temperature coefficient studies in FBAR duplexers for the 1900 MHz PCS band", IEEE Ultrasonics Symposium, 1, 869-874, (2000).

(6) K. M. Lakin, K. T. McCarron, J. Belsick, and R. Rose : "Filter banks implemented with integrated thin film resonators", IEEE Ultrasonics Symposium, 1, 851-854, (2000).

(7) L. Qin, Q. Chen, H. Cheng, and Q. M. Wang : "Analytical study of dual-mode thin film bulk acoustic resonators (FBARs) based on $\mathrm{ZnO}$ and AIN films with tilted c-axis orientation", IEEE transactions on ultrasonics ferroelectrics and frequency control, 57, 1840-1853, 2010.

(8) R. C. Lin, Y. C. Chen, W. T. Chang, C. C. Cheng, and K. S. Kao : "Highly sensitive mass sensor using film bulk acoustic resonator", Sensors and Actuators A: Physical, 147, 425-429, 2008.

(9) R. C. Lin, Y. C. Chen, and K. S. Kao : “Two-step sputtered $\mathrm{ZnO}$ piezoelectric films for film bulk acoustic resonators", Applied Physics A, 89, 475-479, 2007.

(10) R. C. Lin, K. S. Kao, C. C. Cheng, and Y. C. Chen : "Deposition and structural properties of RF 
magnetron-sputtered $\mathrm{ZnO}$ thin films on $\mathrm{Pt} / \mathrm{Ti} / \mathrm{SiN}_{\mathrm{x}} / \mathrm{Si}$ substrate for FBAR device", Thin Solid Films, 516, 5262-5265, 2008.

(11) J. Enlund, D. Martin, V. Yantchev, and I. Katardjiev : "Solidly mounted thin film electro-acoustic resonator utilizing a conductive Bragg reflector", Sensors and Actuators A, 141, 598-602, 2008.

(12)E. Iborra, M. Clement, J. Capilla, J. Olivares, and V. Felmetsger : "Low-thickness high-quality aluminum nitride films for super high frequency solidly mounted resonators", Thin Solid Films, 520, 3060-3063, 2012.

(13) C. L. Wei, Y. C. Chen, C. C. Cheng, K. S. Kao, D. L. Cheng, and C. J. Chung : "Highly sensitive UV sensors based on SMR oscillators", Procedia Engineering, 36, 468-475, 2012.

(14) C. L. Wei, Y. C. Chen, S. R. Li, C. C. Cheng, K. S. Kao, and C. J. Chung : "Effects of reflecting layers on resonance characteristics of a solidly mounted resonator with $1 / 4 \lambda$ mode configuration", Applied Physics A, 99, 271-278, 2010. 